Journal of

\title{
Technologies in Education
}

\section{Tendencies toward Problem-} Setting and Problem-Solving

A Study of Operations Derived from Motivation Strategies 


\section{JOURNAL OF TECHONOLOGIES IN EDUCATION}

www.techandsoc.com

First published in 2014 in Champaign, Illinois, USA

by Common Ground Publishing LLC

www.commongroundpublishing.com

\section{ISSN: 2381-9235}

(C) 2014 (individual papers), the author(s)

(C) 2014 (selection and editorial matter) Common Ground

All rights reserved. Apart from fair dealing for the purposes of study, research, criticism or review as permitted under the applicable copyright legislation, no part of this work may be reproduced by any process without written permission from the publisher. For permissions and other inquiries, please contact cg-support@commongroundpublishing.com.

Journal of Technologies in Education is peer-reviewed, supported by rigorous processes of criterionreferenced article ranking and qualitative commentary, ensuring that only intellectual work of the greatest substance and highest significance is published. 


\title{
Tendencies toward Problem-Setting and Problem- Solving: A Study of Operations Derived from Motivation Strategies
}

\author{
Charles Cox, Pennsylvania State University, USA \\ Johan Wenngren, Luleå University of Technology, Sweden \\ Johan Holmqvist, Luleå University of Technology, Sweden \\ Åsa Ericson, Luleå University of Technology, Sweden
}

\begin{abstract}
User-centered approaches are a key concern for firms' innovation practices, while higher engineering education typically focuses on the technical problem-solving activities. Recently, engineering education has incorporated team assignments for students where they are encouraged to manage open-ended problems. Yet, many students' conduct appears to be "business as usual" and they do not make an attempt to shift their views. Reasons for this behavior need to be investigated to inform the engineering curricula. The purpose in this paper is to demonstrate the impact of distinct orientations on an open-ended design challenge in order to highlight differences, which have implications for learning and education. This study applies familiar educational psychology concepts to the unfamiliar setting of design education, focusing on user needs and acknowledging students' orientations as a possible basis for guiding and accommodating design operations. Engineering design students were divided into two groups based on their individual orientationnamely the mastery and performance oriented types. The homogeneous groups reinforced the individual strategies and the effects on their operations could be observed. The distinct orientations had an impact on the open-ended design challenge. Results indicate considerations for conflicts between solving and setting, which might affect the involvement of users and their needs as resources in early product development. This study addresses how individual orientations in homogeneous groups have an effect on user-centered design in open-ended design tasks. Highlighting differences contributes to understanding challenges in innovation activities. The study indicates that students need different guidance and coaching to match their orientations.
\end{abstract}

Keywords: Mastery Orientation, Performance Orientation, Team-Based Design, Innovation

\section{Introduction}

$\mathrm{T}$

The success of an innovation relies heavily on the generation of content upfront in the design process, where the designers start to think about a solution. Schön (1983) stresses the importance of solving the right problem, that is, to frame the problematic situation adequately. A dilemma in product development in general, and in innovation projects in particular, is that the information about the users, their situation and a potential solution are vague at this stage. There is a risk that designers, in order to solve the dilemma, interpret the situation in terms of their own wants and desires, leading to solutions they would like to own themselves (Faste 1987). A recommendation to avoid solving the wrong problem is to go to the users and learn from their activities and behaviors (e.g., Patnaik and Becker 1999). This approach is used by a few companies, e.g., IDEO (Kelley 2001) and branded as Needfinding.

However, it can be argued that when this approach is realized in product development there can still be a difference in preferences. The designers can, for example, focus on an existing product and how it is used and then search for how to improve the goods as such, or they can focus on the users, their goals and the context where they act in order to find new solutions. Efforts at combining these two focuses are rare in industry, but due to an increased acceptance of qualitative methods (Patnaik and Becker 1999), there could be a window of opportunity for such a two-sided perspective (Brown 2009).

Since managing user information is more of an explorative effort than obtaining a single right answer from the user, the efforts to acquire and interpret user data should be supported. If we assume that the activities of managing user information relate to a designer's tendency to

Journal of Technologies in Education

Volume 10, 2014, www.techandsoc.com, ISSN 2381-9235

(C) Common Ground, Charles Cox, Johan Wenngren, Johan Holmqvist, Åsa Ericson,

All Rights Reserved. Permissions: cg-support@commongroundpublishing.com 
adopt a certain orientation when framing and solving the design task there are possibilities to study this for the purpose of understanding how the individual's orientation might affect early planning and design activities. If diversification is sought for when conducting a design challenge, making an effort to frame the problem adequately before suggesting solutions is utmost importance. Solving an open-ended problem involves constraints, trade-offs, feedback loops, decision-making and other perspectives that cannot be foreseen from the start (Moore et al. 2013). Designing requires acquaintance and practice with these challenges.

Previous experiments in architectural design education (e.g., Demirbas and Demirkan 2003) showed that different orientations affect performance of the processes chosen to address a design problem. Instead of claiming that there is one orientation that optimizes all design processes, it is crucial that an instructor understand the advantage of exploring a continuum of activities that challenge the design learners. Collaborative design activities are difficult to teach and need to be practiced by students, since engineering skills are learned through shifting between theory and practice (Dym et al. 2005). It seems crucial that an instructor understand how to encourage students to shift among appropriate learning styles and between different individual orientations. For example, in design work the behavior of novices has been associated with a sequential approach to identify and solve sub-problems, whereas experienced designers practice a top-down approach by exploring the problem-setting before solving sub-problems (Cross 2004; Litzinger et al. 2011). For novices then to examine their approaches reflectively could prove a benefit to engineering practice in that if the individual preferences for dealing with problems were made explicit, a design team could make use of those preferences and direct members having suitable tendencies into appropriate phases of problem-setting or problem-solving.

To study this, we have set up an experiment with engineering design students and presented them with an open-ended design challenge. The students were divided into two homogenous groups based on their individual motivation for approaching design challenges (Pintrich, Marx and Boyle 1993). The design challenge concerned a simulation of relief in the aftermath of a recent natural disaster in the Caribbean that had displaced hundreds of thousands people, leaving them homeless for the foreseeable future.

\section{Research Questions}

Pintrich, Marx, and Boyle (1993) divide learning preferences into the two categories, mastery orientation and performance orientation, their work relates to the earlier work by Dweck (1986). That is, applying a mastery orientation tends to focus on understanding a task or situation in more depth, for example to become more knowledgeable about a situation. While applying a performance orientation, the activities gravitate toward exploiting existing knowledge. Also, mastery orientation and performance orientation could be seen as having similarities with the concepts problem-setting and problem-solving as suggested by Schön (1983). Simply, problemsolving builds on the characteristics of exploitation and converging activities (Stempfle and Badke-Schaub 2002), and problem-setting builds on the characteristics of exploration and diverging activities (Benner and Tushman 2003).

This study is based on two assumptions. The first assumption is that an open-ended design challenge is approached by agents having a tendency to, firstly, apply either a mastery/problemsetting or performance/problem-solving. The second assumption is that an individual's orientation for mastery or performance, in this study reinforced in a team, has an impact on the choice of design approach. To understand the impact of distinct orientations to a design challenge, we thought that teams of all mastery-oriented and all performance-oriented individuals would more likely demonstrate the reinforcement or suppression of preferences than mixed teams would. 
This led to the formulation of the following research questions:

- How are mastery and performance orientations expressed as operations in homogeneously aligned teams?

- How would operations inform — by degree or by kind - a user-oriented approach to a design task?

\section{Methodology}

The students participating in this study were undergraduate engineering design students, in an architecturally orientated program. The students were anticipated to work in groups and they were bound to assess the assignment themselves. Thus dealing with a high degree of ambiguity, this is in contrast to most of their other courses where the tasks and assignments are more welldefined. Not everyone feels comfortable right away with confronting ambiguity, and we expected individual students to cope with this discomfort by resorting to either one or the other of two fundamental individual strategies.

In the progress of design operations, imposing clarity on ambiguity demands purposeful engagement and directed effort from undergraduate students at a level that is demanding for many of them, especially since much of their previous education has directed them toward defensibly exact answers to well-defined and well-structured questions, typically not at the discretion of a learner to challenge. And, as Kilgore, Atman, Yasuhara, Barker and Morozov (2007) point out, even many undergraduate programs in engineering do not deal with design until the very end of that course work (cf. Atman et al. 1999; little had changed in the intervening eight years).

The students were all in their middle to last part of a degree program, so they were not yet experts, but rather experts in the making. This study extended the conditions of those studied in Cross and Cross, 1995 because we were observing novice designers in teams pursuing an architectural design, whereas those authors were working with experienced designers working on a product design. The study was administered in its entirety during a regularly scheduled class meeting in the project course, in one afternoon, in a workshop format that lasted four and a half hours. The workshop was divided into three main sessions of roughly equal length, with breaks in between. Basically, the workshop agenda was inspired by the product development processes proposed in Ulrich and Eppinger (2008) and Patnaik and Becker (1999). The development process outlined during the workshop was a simplified model of early stages of design including user-orientation: user analysis, concept generation, concept selection and prototyping.

MSLQ (Motivated Strategies for Learning Questionnaire, constructed and reported by Pintrich et al. 1993) was used to divide the students into two groups distinguishing between students' preferences, i.e. who would be considered performance-oriented (e.g. excelling in competition) and who would be considered mastery-oriented (e.g. understand the task in depth). The section in MSLQ regarding motivation strategies was used in this study. This choice is in keeping with McKeachie (1995) who posits that orientation is one of three factors that predict engineering design learners' performance. The other two factors being knowledge and intelligence, the analysis of which constructs being of marginal use to this study. How MSLQ has been used is reported in more detail in a previous publication (Holmqvist et al. 2011). The students were then formed into mastery-oriented and performance-oriented teams consisting of 6 students in each team.

A short introduction was given in the beginning of the workshop, in which the students were assigned to analyze and address shelter solutions for people suffering from a natural disaster in the Caribbean where hundreds of thousands of people had been left homeless both suddenly and for the foreseeable future. Throughout the workshop, the teams were separated from one another, although they met in the end and each team made a presentation to the other. The two teams were 
thus provided with an adjacent pair of classrooms in which to begin their work. The two classrooms were prepared with material that could be of use, such as whiteboards, papers, pens, etc. The material provided was of equal quality and quantity to both teams. The short introduction in the beginning of the workshop was intended to be the material from which the students were to derive their design problem. The introduction included a presentation of a 15minute video, showing an actor portraying a refugee displaced by the disaster, and recorded in front of a panoramic backdrop view taken from the actual disaster scene. The actor made an appeal for help to the students, underscored by the threat of further hostile weather conditions. The video clip was designed to simulate a journalist reporting from the site, the scene being an interview with a civilian at the disaster area, asking for help. The students also were provided with a one-page document outlining the situation's open-ended problematic manner, i.e. there were no obvious guidelines leading to exact or quantifiable answers. This introduction gave the students information about the context, but they were free to interpret the problematic situation into a more precise design problem for themselves.

To aid the work two operations for ideation were presented. The first was one commonly used for brainstorming, where the participants were told to try to be positive in their responses to each other's suggestions, to generate as many alternative solutions as possible, to build on each other's ideas, to be open minded, and to contribute actively (Kelley 2001). The second operation was presented as a simple user-orientated process involving personas (Grudin and Pruitt 2002) where the students were told to invent and describe a range of typical stakeholders, age, occupation, needs, etc.

In summary, the researchers scaffolded content operations through the distribution and review of instructional material, suggesting that one alternative being considered by relief agencies was a massive importation to the site of rapidly deployable shelters in the form of shipping containers. Using 20 foot long standard shipping containers as a basis in their design considerations was presented as a constraint for the task, and the students were asked to exemplify their solutions using cardboard prototypes.

The workshop was divided into 3 main sessions, called (1) identifying stakeholders and needs, (2) concept generation, and (3) prototyping and presentation. Prior to the third session the students first played a computer game simulating a context similar to that of their design challenge. The computer gamed is provided by the Red Cross (Red Cross 2012) and it was introduced as inspiration for the prototyping. Then the students made physical prototypes of their solutions, e.g. drawings, charades, physical artifacts, stories. Thereby, the prototyping activities can be categorized as rough in appearance, but necessary for the communication of novel ideas (Brown 2009; Schrage 2000). Parts of the activities in this session, as also in the categorization in between the sessions, include efforts to compare, assess and evaluate alternatives that would inform a successive action. As a final step both teams met in one classroom and each team presented its identified needs, concepts and problem solution prototypes to the other team. The activities in the sessions were both divergent, i.e., generative in nature, and convergent, i.e., selective in nature (Bánáthy 1996), that is operations typically included in design work. Additionally, each of these categories can deal with both content, as in what is being investigated, i.e. task-work, and process, as in as in how an investigation occurs, i.e. team-work (Stempfle and Badke-Schaub 2002). Seen from the perspective of the challenge under scrutiny, two types of operations could have directed the actions, either exploitation or exploration (Benner and Tushman 2003). Also, each of these actions can deal with task-work and team-work, i.e. divergent/explorative and convergent/exploitative.

The researchers, who alternated their time spent with each team, clarifying or otherwise answering questions related to the assignment, attended all sessions. Likewise, in this study the questions posed to students were intentionally crafted to be open-ended, which was eased by the circumstances that no definitive response to the disaster had occurred in reality. Each session was recorded on video for later analysis, via camcorders located on both team sites. The videotaped 
material provided primary data for analysis. Sketches and students' notes from the workshop provide a secondary source of material. The researchers have, as best as they can, made an effort to increase the quality in the analysis. First, the videotaped material was analyzed in a non-cross sectional way (Mason 1996). This means that the researchers did not use pre-defined codes; rather particular behaviors are noted while watching. Notes were taken during the first analysis, but the researchers did not yet discuss the observations with each other. Second, based on each researcher's notes, the sequences found relevant for the study were further analyzed by the whole group of researchers. Excerpts have been taken from these sequences since they were found to be typical for the teams' discussions. The second round of analysis was guided by the categories derived from not only Bánáthy's (1996) divergence/convergence, and Stempfle and BadkeSchaub's (2002) content/process, but also Schön's (1983) distinction between problem-solving and problem-setting. These categories were applied to find patterns in the data. The third round of analysis focused on finding quantitative measures. To do this, researchers kept track of how many concepts were generated, number and kind of stakeholders taken into account, and the time spent on user-oriented activities.

\section{How the Teams Explained the Open-ended Problem}

Excerpts from the recorded conversation in the workshop are provided to exemplify how the students reasoned, and these can be seen as typical for the teams' discussions. Further, the excerpts are chosen, not to describe the students' ideas and solutions, but to describe how their conversations were oriented towards performing a certain task or master the processes of gaining insights into the user situations.

\section{Session 1: Identifying Stakeholders and Their Needs}

The performance-oriented team talked about actors in the situation as sponsors for material, help organizations, companies that could be solicited, and governments, in other words, agencies and institutions. They made a list of those actors, but the list did not end up in a description of personas. Also, they did not feed that information into the design challenge. Instead, they jumped into solutions after only a few minutes, such as this response to an utterance about how to keep order during the rebuilding of the society.

B: "Then we need someone that could keep the order, police officers or the like..." (Performance-oriented, 5.35 min Session 1)

This early and rapid delimitation of the design space in relation to their interpretation of the task can be observed in several discussions throughout the whole first session in the workshop. For example, when one of their members suggests including transportation of the containers to the site as a vital need, the performance-oriented team agreed that investigating roads at the site was not included in the situation.

F: "What about the roads there, do we know anything about them?"

B: "No, we should not care about that. We should not worry about it." [The other team members concur]. (Performance-oriented, 25.05 min Session 1)

The mastery-oriented team discussed stakeholders on another level of abstraction from the beginning, and thus performed quick iterations of describing the situation in order to establish the scope for the task. After a short period of silence following the initial search for a scope, one of the team members suggested: 
G: "Well, can't we say that people in different ages has different needs? A baby has specific needs and a middle-aged man has others?” (Mastery-oriented, $5.30 \mathrm{~min}$ Session 1)

The mastery-oriented team's discussions ended up in a list of people with different skills, different ages, and different disabilities, and they assigned distinct characteristics and names to a variety of people affected by the disaster, i.e. they developed personas. Also, the masteryoriented team acknowledged alternative interpretations of the design challenge during the iterations. The mastery-oriented team started by deducing needs that are shared for their stakeholders, what the team calls basic needs:

H: "We could go with the basic needs? Needs that everyone has!"

I: "Water?"

G: "Yeah water, definitively."

J: "Food"

G: "Water, food"

K: "Shelter"

G: "Shelter... and then, all of them, to be sustainable in the future we need to find a way to earn money, work and, to get a job or something, if they are going to rebuild their society or... there is a need to for them to earn money to make a living, but I don't know."

H: "Yes..."

I: "Resources"

G: "I guess that they don't need heat in their homes, but perhaps shadow from the sun?"

[the team takes up the discussion of basic needs again]

[...]

I: "I guess relatives and friends?"

G: "Yes, social needs"

H: "Ehh... do they need education, do they need school? Is that a basic need?

G: "It is not a basic need but the world would probably be a better place"

I: "Yes"

H: "He [refers to the man in the video] said that they don't have electricity and that they don’t have sanitary solutions.” (Mastery-oriented, 7.10 min Session 1)

Whereas the performance-oriented team remained confident with their investigation of stakeholders at one overarching level of abstraction. By this approach, they not only suggested solutions early on, but also their activities of planning, scoping and user analysis can be described as convergent/exploitative. From their list of actors, the performance-oriented team embarked on finding needs of those actors. One of the team members led the session in this manner:

A: "Ok, what kind of need do we have when it comes to the sponsors? We got to have containers, and some stuff to make electricity..."

B: "Water?" [the other team members agree, and B continues]. "Water, food, garbage recycling, sanitations."

A: “Ok, so how are we going to get water... ehh... just dig a hole?” [the rest of the team giggles]

B: "Yeah... maybe!... Maybe they don't have the equipment?"

C: "Probably not."

B: "So you... build... Can they take rainwater instead?" (Performance-oriented, 7.15

min Session 1) 
All students had been introduced to Maslow's hierarchy of needs (Maslow 1970) in a previous course, but comparing how the performance-oriented team managed their discussion on needs versus how the mastery-oriented team managed theirs show a difference in approaches to the task. The performance-oriented team did not take the discussion beyond what Maslow categorizes as deficiency needs, being those fundamental needs that are necessary to survive, e.g. water, food and in the reasoning of the performance team, garbage handling. They did not think about future needs or progressively changing needs, e.g. growth needs, like being part of a social context and knowledge, while the mastery-oriented team went further with such an investigation. Also, interpreting the dialogue, we find that the performance-oriented team related their identified needs to physical objects, e.g. shovels, trucks, etcetera. Or to solutions, e.g. police officers as a solution to preserve order. By doing this, the performance-oriented team made a direct interpretation of need statements into solutions, skipping the exploration of situation and people. When comparing these two ways of reasoning, we interpret the performance-oriented team as focused on solving the given task by addressing the implementation of existing solutions, and the mastery-oriented team as learning more about the situation to solve the given task by inventing new or better solutions. For the sake of the assigned design challenge, both teams did account for stakeholders and needs (to differing extents), and both made an effort to investigate a situation to find a problem to be addressed, yet their design problems were differently scoped and planned. The mastery-oriented team spent a slightly longer period of time on discussing the design challenge, thus performing activities that can be described as divergent/explorative

The performance-oriented team framed the design challenge by focusing on these parts:

- $\quad$ provide shelter

- arrange transportation

- move containers

- $\quad$ provide a place to sleep

The mastery-oriented team framed the design challenge by focusing on these parts:

- $\quad$ conditions of living

- rebuilding a society

- interaction

- $\quad$ social areas

\section{Session 2: Concept Generation}

The performance-oriented team divided the work among the team members in order to work faster and three students each focused on two distinct areas, namely water and food/other material. In their discussion how to divide the areas they seemed to make an effort to state the boundaries to not enter each other's area of responsibility when suggesting solutions, but they did not specify "other material". Three students from the performance-oriented team assigned to manage the water problem are discussing how the need for water can be solved:

B: "Ok, we can ship it to the place, drill a hole or collect rainwater. It is these three solutions..."

C: "Ok, we need water treatment plants."

B: "Not if we collect rain water. It is clean as it is."

C: "But... no, shouldn’t you clean it..."

$[\ldots]$

C: "If we drill for water we need equipment and drills..."

B: “And, you need personnel” 


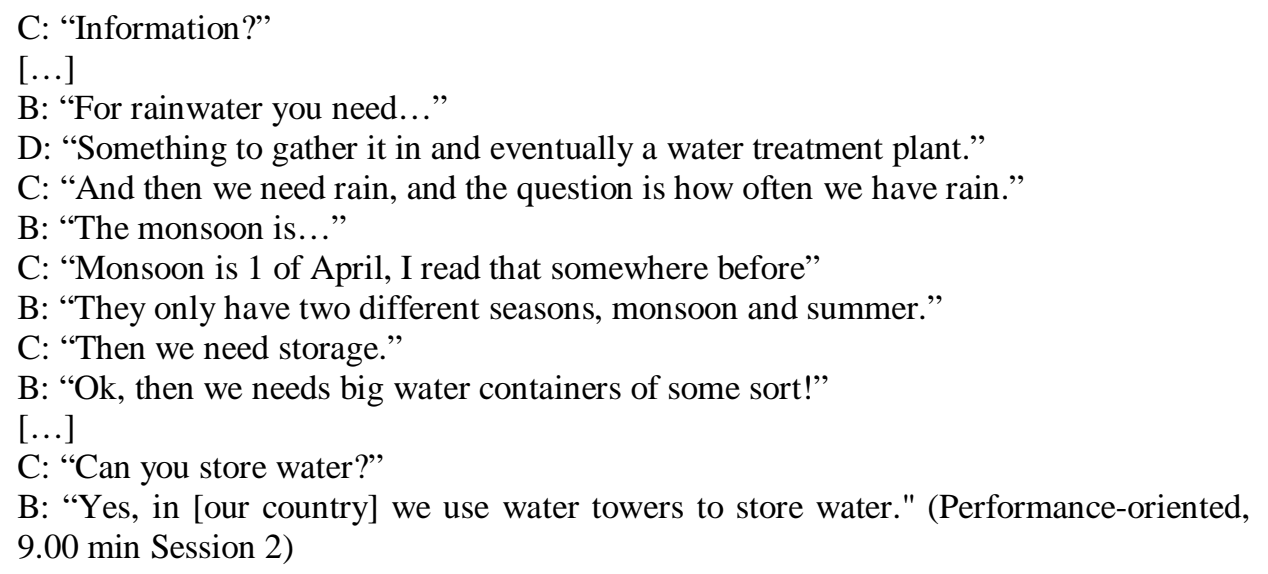

The performance-oriented team circumscribed the design challenge from the start, but also, as it seemed, the team found it comfortable to elaborate on only the three solutions that they had previously identified, i.e. saying "ok" as a response to each other's utterances indicates agreement and decision-making rather than investigation of alternatives. In comparison to the mastery-orientated team, the performance-oriented team confined their discussion to objects, rather than human beings. This interpretation is based on how questions in the team are related to the (previously defined) solutions, and as it seemed, as long as the information brought clarity to the progress of the solution at hand, the team appeared satisfied to accept and incorporate it.

The three performance-oriented students that were assigned to manage the water problem continued their discussion of how to get clean water to the site. They delimited their part of the design challenge even further, since they assumed that the remaining 3 students from their team had already solved a part of their assignment. They then shifted to figuring out how to get the containers to the site:

C: "But, if they [referring to the other group] have solved the food and other material, then it is fine. I think the people need somewhere to sleep.

C: "What they needed was to sleep, eat ..."

B: "Yes, but, I was thinking on how we transport it there. How we ship it there? How we transport it?”

D: "But, it depends if we use military tents on a car then maybe..."

B: “...We will ship it anyway."

B: “So... maybe we are done after all?” (Performance-oriented, 39.06 min Session 2)

The performance-oriented teams' dialogue is seemingly based on probing whether they had managed the task or not. Student $C$ is making an attempt to check the list of needs that they made in the first session, but is interrupted by student B who seems dissatisfied with how they have managed the transport problem, i.e. "yes, but...”. This can be interpreted as the students find it important to check that their solution could be related back to the requirements that they had decided from the beginning, while B found it more important to address the information given in the design challenge. Any problem that was not agreed upon for inclusion within the task was then excluded from their investigation.

The mastery-oriented team conducted a brainstorm to find solutions for, as they had defined the topic, temporary housing for the people in the disaster area. One team member came up with an idea (student L) and two others (student $\mathrm{G}$ and $\mathrm{H}$ ) then took the lead in the dialogue and started to talk about how to modify the containers as homes. 
H: "But doesn't the container get very hot in the sun? ... We have a solution were we could use the rest of the material as a roof." [Visualizing with her hands]

L: "Yeah, and there are lots of hillsides on the site that we could use."

G: "Yes, so we could follow the hillsides."

L: "Yes"

H: "You mean the hillside..."

L: "Yes if we fold the roofs like this." [Draws on the whiteboard]

G: "Yeah"

L: "Yes"

H: "And we use these to create houses here..." [Points on the sketch].

H: "Is it possible that you stack the containers like this.” [Points on the sketch]

[...]

$\mathrm{K}$ : "Ok, during the rain season I think you must do that."

$\mathrm{H}$ : "Yeah, and during another earthquake it would be better."

G: "What happens during rain season when..." [Starts to gesture]. (Mastery-oriented, 14.30 min Session 2)

The mastery-oriented team made use of their distinction between solutions, e.g. a roof, and needs for living inside a modified container, e.g. habitable temperature inside. This team typically built on their ideas by acknowledging each other's utterances, and starting new rounds of ideation to improve the ideas. The mastery-oriented team had another approach in managing their work: they stayed together as one group throughout the session. Although they had sideconversations two-and-two, after such a discussion, they usually shared their ideas with the whole group. So, the work was divided, but not the group. For example, on one occasion different concepts came up in the side-conversations, and this idea was brought up for discussion by the whole team when gathered in front of their whiteboard.

L: "If we have a container, and that is were they are living!"

G: "Ok, so you mean that, if we stack them on top of each other you can use this area [pointing at the sketch on the whiteboard] for something else. Since you already have walls and roof from the container above?"

L: "Yes, it's a simple construction"

G: "Ok, so you mean that it can be used as a roof?"

L: "Yes."

$[\ldots]$

G: "Yes, they can still use this area [pointing to a sketch], and just put a simple roof here, then you can have a place to sit underneath."

$\mathrm{J}$ : "And... I think we can reuse a lot of material that are taken away from the container"

G: "Yes, I actually like our idea, that we came up with, or that you came up with." [refers to an earlier idea]

G: "They are used to live in small houses... so they can use old material to bend it [gesture like she is referring to a roof] ... and then you add small containers that are like small tunnels, and then they can use them for living as well.” (Mastery-oriented, 10.05 min Session 2)

The mastery-oriented team started to combine ideas into a concept, still investigating possibilities to refine the ideas. That is, the definition of the task evolved as their investigation of ideas evolved. It should be noted that the performance-oriented team, despite coming up with solutions already after a few minutes, did not manage to settle the task before time was called or before the mastery-oriented team did. 


\section{Discussing Tendencies in the Teams Operations}

The mastery-oriented team and the performance-oriented team approached the design challenge differently and by applying user-orientation differently. A note here is that the study does not seek to find out which approach is the best, because a mastery orientation is not always superior to a performance orientation, and vice versa. Also, it could be supposed that an individual's orientation is not, and should not be, stable over time. For example, being a design learner not yet possessing expertise in the area might result in an approach where that individual is more prone to rely on a well-defined structure, and hence to direct his or her operations to find such a process. Gaining practical experience in the area might encourage more explorative and divergent activities, once a structure is now part of the individual's experiences. It can also be supposed that an individual might apply a different orientation depending on the task at hand. For example, in cases where the design task is more concrete, as in incremental improvement of a thing, it is doable to set up a goal and measurements beforehand. Hence a performance orientation would probably be an efficient approach. While in the case of creating new solutions or addressing unknown markets it is not doable to set up a goal beforehand, thus a mastery orientation would probably be needed.

From the sketches, displayed in Figure 1 below, it can be seen that the performance-oriented team worked with the transportation problem as their core design challenge to provide housing at the site. Thus, an interesting phenomenon did happen here: the performance-oriented team did not apply their knowledge of design directly onto the challenge, either by designing a place for temporary homes or redesigning the containers. The containers were more or less still containers in the final presentation, yet used for the purpose to get shelter, eat and sleep.

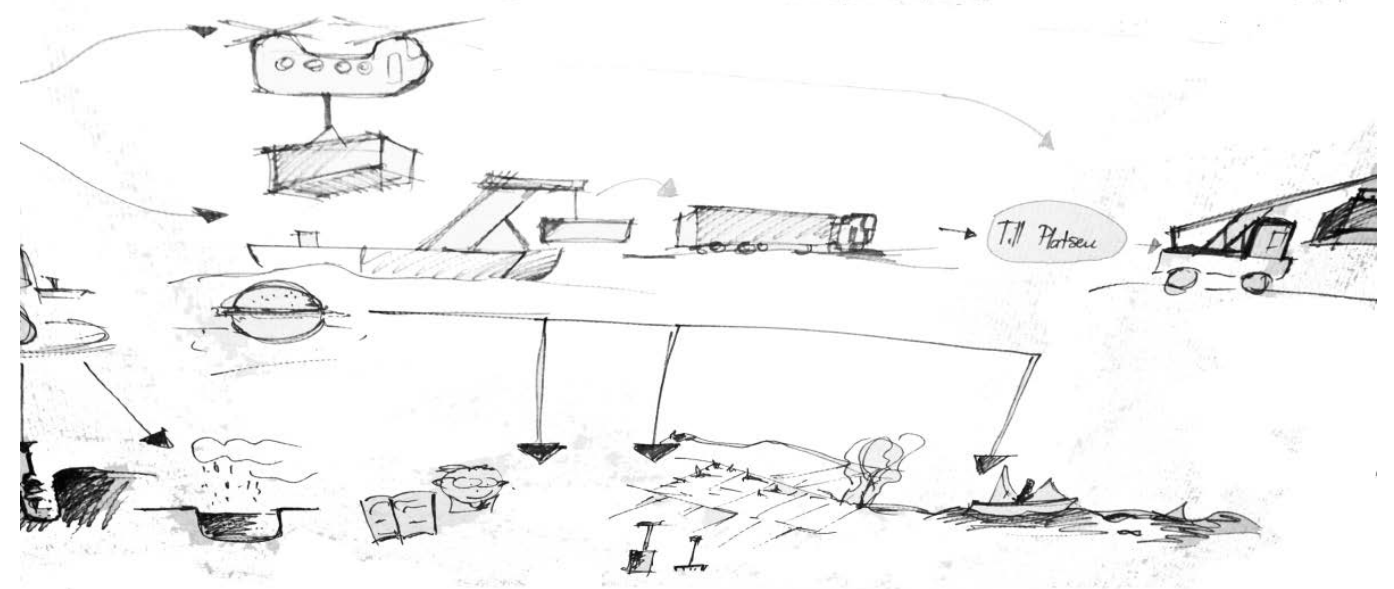

Figure 1. The Performance-oriented Team's Storyboard (showing helicopters, boats, lorries, and wheel loaders transporting the containers, i.e. the solution)

The mastery-oriented team presented their first solution at the beginning of Session 2 in which they were investigating additional ideas. They made an effort to build a wider picture than just transportation, by visualizing the relationships between different aspects (see their sketch in Figure 2). Under realistic circumstances the mastery-oriented team might have implemented their design of temporary housing including social areas, since they addressed the problem in a much broader sense, reflecting on possible aftershocks and other conditions on the site. In the final presentation they had applied some of their knowledge of design onto the challenge. The containers were redesigned for the purpose to get shelter, eat, sleep and have a social life. 

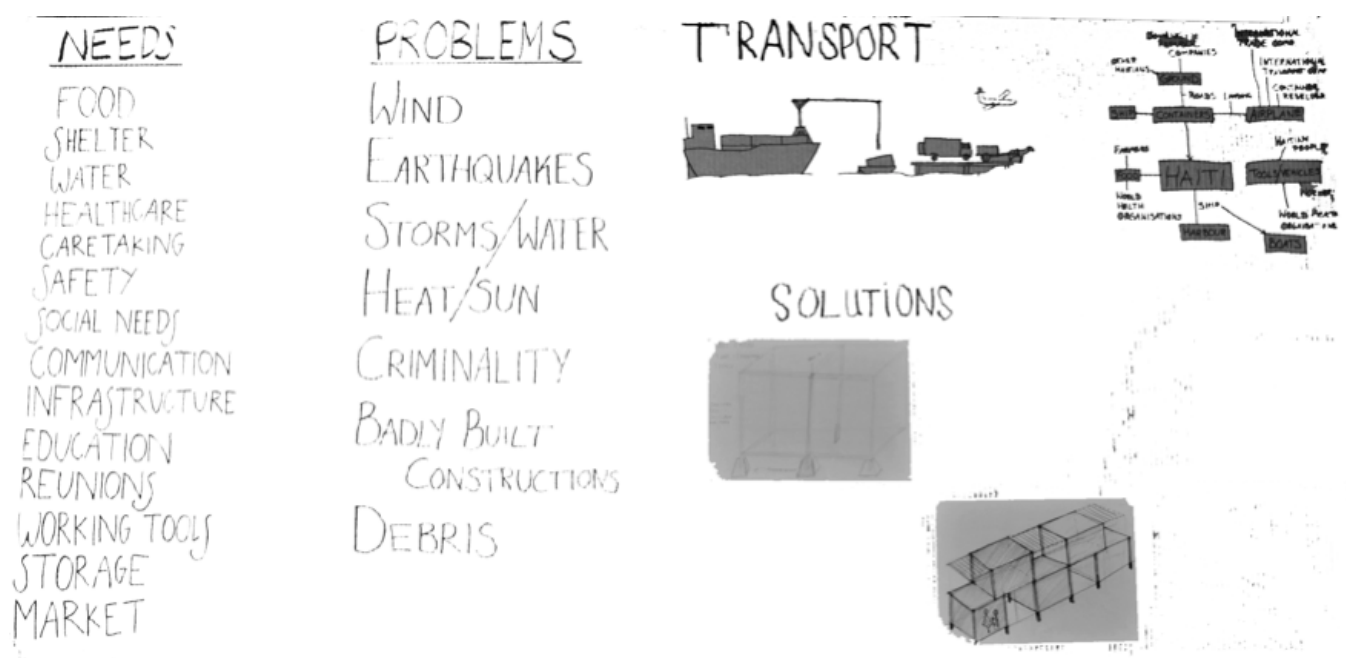

Figure 2. The Mastery-oriented Team's Storyboard (showing needs as keywords, problem areas, some sketches of alternative solutions, and in the upper right corner, a map to visualize relationships)

A comparison of the teams' operations shows that the performance-oriented team had a tendency to manage the challenge on an overarching level, applied an exploitation approach to solve the problem. Hence, such a design approach aligns with a tendency to focus too early on problem-solving activities, which is hampering for an open-ended design challenge. The mastery-oriented team managed both the problem-solving activities, but also the exploration of the design challenge. Such a design approach aligns with a tendency to incorporate problemsetting in terms of user-orientation. Schön (1983) suggested that problem-setting is a part of a problem-solving process, and that naming things and framing the context, i.e. conducting problem-setting is not a technical problem. Basically, as observed here tendencies towards one or the other orientation might occur based on individual motivation strategies, and those had an effect on how the open-ended problem was approached.

\section{Conclusion and Future Work}

The research questions posed were how the individual orientations were expressed as operations in homogeneously aligned teams, and how such operations informed a user-oriented approach. It is important to note that the study is delimited to an open-ended design challenge, where understanding users is of utmost concern. The performance-oriented and the mastery-oriented team executed the design task differently, and in comparison the mastery-oriented team exceeded in bringing in a user perspective. The opposite case, i.e., assigning a clearly defined design task to the mastery-oriented team, could be expected to show shortcomings in how such a problem is approached. Yet, the study indicates that, in real teaching situations, considering instructions in relation to the individual operations is not only important for learning, but also not trivial. The study presented here can thus align how the orientations and tendencies related to the teams' investigations of the design challenge (see Table 1). 
Table 1. Relation between Orientation, Tendency, and Investigative Approach in the Design Challenge

\begin{tabular}{|c|c|c|c|c|}
\hline $\begin{array}{c}\text { Individual } \\
\text { orientation }\end{array}$ & $\begin{array}{c}\text { Design } \\
\text { approach } \\
\text { tendency }\end{array}$ & $\begin{array}{c}\text { Type of investigation } \\
\text { of the task }\end{array}$ & $\begin{array}{c}\text { User- } \\
\text { centered }\end{array}$ & Solution basis \\
\hline $\begin{array}{c}\text { Performance } \\
\text { oriented }\end{array}$ & Problem-solving & Exploitation & $\begin{array}{c}\text { Users as } \\
\text { objects }\end{array}$ & $\begin{array}{c}\text { Existing ideas, } \\
\text { requirements }\end{array}$ \\
\hline $\begin{array}{c}\text { Mastery } \\
\text { oriented }\end{array}$ & Problem-setting & Exploration & $\begin{array}{c}\text { Users as } \\
\text { people }\end{array}$ & Novel ideas, needs \\
\hline
\end{tabular}

The study has delimitations, not only in terms of number of students involved, gender, the time available to observe them, and the expediency of adding and losing participants due to the day-to-day attendance vagaries that plague any course, but also in terms of scope. And, admittedly, any or all of those factors could have affected our results to some extent, although we believe that the study indicates interesting issues on operations in open-ended design situations. Therefore, a number of suggestions for future studies need to be addressed. To increase trustworthiness from the division into two homogeneous groups, similar experiments have to be repeated. We have not noted any difference in scale, as in how the operations differ between what was expected from individuals and what was actually used in teams. This was anticipated as consequence of using homogeneous teams. Thus, mixing the two orientations into a heterogeneous team would be beneficial to investigate how both orientations would inform the design task at hand, and what kind of operations are needed to sustain an effective approach for user-orientation in product development.

Finally, the MSLQ instrument includes a part that focuses on learning strategies, which we have not included in our study. But, this is suggested for future research activities. Such an experiment could inform educational situations in more detail. Moreover, work addressing students thinking styles, for example, Volpentesta, Ammirato and Sofo (2012) would provide deeper insights into the practice of interchangeably applying different rationales in project-based learning situations, and hence will be considered in future studies. 


\section{REFERENCES}

Atman, C., Chimka, J., Bursic, K. and Nachtmann, H. 1999. “A comparison of freshman and senior engineering design processes.” Design Studies, 20(2), 131-152.

Bánáthy, B. 1996. Designing Social Systems in a Changing World (1st ed.). New York: Plenum Press.

Benner, M. and Tushman, M. 2003. "Exploitation, exploration, and process management: the productivity dilemma.” Academy of Management Review, 28(2), 238-256.

Brown, T. 2009. Change by design: how design thinking transforms organizations and inspires innovation (1st ed.). New York: HarperCollins Publishers.

Cross, N. and Cross, A. 1995. "Observations of teamwork and social processes in design." Design Studies, 16(2), 143-170.

Cross, N. 2004. "Expertise in design: An overview.” Design Studies, 25(5), 427-441.

Demirbas, O. and Demirkan, H. 2003. "Focus on architectural design process through learning styles.” Design Studies, 24(5), 437-456.

Dym, C.L., Agogino, A.M., Eris, O., Frey, D.D. and Leifer, L.J. 2005. "Engineering design thinking, teaching, and learning.” Journal of Engineering Education, 94(1), 103-120.

Dweck, C.S. 1986. "Motivational processes affecting learning.” American Psychologist, 41(10), 1040-1048.

Faste, R. 1987. "Perceiving needs." Proceedings of the Society of Automotive Engineers Future Transportation Technology Conference and Exposition (pp. 419-223). Seattle: Washington.

Grudin, J. and Pruitt, J. 2002. "Personas, participatory design and product development: an infrastructure for engagement.” In T. Binder, J. Gregory and I. Wagner (Eds.), Proceedings of the Participatory Design Conference (pp. 144-161). Sweden: Malmö.

Holmqvist, J., Wenngren, J., Cox, C., Ericson, Å. and Bergström, M. 2011. "Setting up a research experiment-How does personal motivation affects problem settings?” Proceedings of International Conference on Research into Design. India: Bangalore.

Kelley, T. 2001. The art of innovation (1st ed.). USA: Currency Doubleday.

Kilgore, D., Atman, C., Yasuhara, K., Barker, T. and Morozov, A. 2007. "Considering context: a study of first-year engineering students.” Journal of Engineering Education, 96(4), 321334.

Litzinger, T., Lattuca, L.R., Hadgraft, R. and Newstetter, W. 2011. "Engineering Education and the Development of Expertise.” Journal of Engineering Education, 100(1), 123-150.

Maslow, A.H. 1970. Motivation and personality (3rd ed.). New York: R.R Donnelly and Sons Company.

Mason, J. 1996. Qualitative Researching, Sage. London.

McKeachie, W. (1995) Learning styles can become learning strategies. The National Teaching and Learning Forum, 4(6), 1-3.

Moore, T.J., Miller, R.L., Lesh, R.A., Stohlmann, M.S. and Kim, Y.R. 2013. "Modeling in Engineering: The Role of Representational Fluency in Students' Conceptual Understanding." Journal of Engineering Education, 0(0), 1-38.

Patnaik, D. and Becker, R. 1999. "Needfinding: the why and how of uncovering people's needs." Design Management Journal, 10(2), 37-43.

Pintrich, P., Marx, R. and Boyle, R. 1993. "Beyond cold conceptual change: The role of motivational beliefs and classroom contextual factors in the process of conceptual change.” Review of Educational research, 63(1), 167-199.

Pintrich, P., Smith, D., Garcia, T. and McKeachie, W. 1993. "Reliability and predictive validity of the Motivated Strategies for Learning Questionnaire (MSLQ)." Educational and Psychological Measurement, 53(1), 801-813. 
Red Cross - Computer game. (n.d.). Retrieved August 27, 2012, from http://redcrossthegame.nl/site_en/.

Schrage, M. 2000. Serious play: how the world's best companies simulate to innovate (1st ed.). Boston: Harvard Business School Press.

Schön, D.A. 1983. The Reflective Practitioner: How Professionals Think in Action (1st ed.). New York: Basic Books.

Stempfle, J. and Badke-Schaub, P. 2002. "Thinking in design teams: an analysis of team communication.” Design Studies, 23(5), 473-496.

Ulrich, K. and Eppinger, S. 2008. Product Design and Development (4th ed.). New York: McGraw-Hill.

Volpentesta, A. P., Ammirato, S., Sofo F. 2012. "Collaborative design learning and thinking style awareness." The International Journal of Engineering Education 28(4), 948-958.

\section{ABOUT THE AUTHORS}

Charles Cox: Instructor of Engineering Design and Architectural Design, Pennsylvania State University, University Park, PA, USA

Johan Wenngren: PhD Student, Product Innovation, Division of Innovation and Design, Luleå University of Technology, Luleå, Sweden

Johan Holmqvist: PhD Student, Product Innovation, Division of Innovation and Design, Luleå University of Technology, Luleå, Sweden

Dr. Åsa Ericson: Head of Research, Product Innovation, Division of Innovation and Design, Luleå University of Technology, Luleå, Sweden 
Journal of Technologies in Education is one of the four thematically focused journals that comprise the Technology Collection and support the Technology, Knowledge, and Society knowledge community - its journals, book series, and online community.

The journal focuses on curriculum and instruction in the era of networked computing. It explores issues relating to e-learning and pedagogy, the challenges of engagement, multimodal communications and multiliteracies, and the virtual university.

Journal of Technologies in Education is a peer-reviewed scholarly journal.

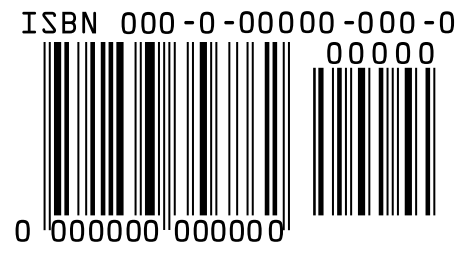

